\title{
Electrochromic behavior of Prussian Yellow
}

J. Agrisuelas ${ }^{\mathrm{a}}$, C. Delgado ${ }^{\mathrm{a}}$, J.J. García-Jareño ${ }^{\mathrm{a}}$, C. Moreno-Guerrero ${ }^{\mathrm{a}}$, A. Roig ${ }^{\mathrm{b}}$, F.

Vicente $^{\mathrm{a}}$

${ }^{a}$ Departament de Química Física, Universitat de València. C/ Dr. Moliner, 50, 46100, Burjassot, València, Spain.

${ }^{\text {b}}$ Departament de Quimica Física i Analítica, Universitat Jaume I, 12071, Castellón, Spain

Prussian Blue films were studied by in situ electrogravimetric and spectroelectrochemical methods during the electrochemical oxidation to the Prussian Yellow form. Spectroelectrochemical studies detected important absorbance changes during electrochemical experiments at $430 \mathrm{~nm}$ and $690 \mathrm{~nm}$ corresponding to the appearance of the yellow form and to the disappearance of the characteristic blue color. These changes of absorbance were well related with the voltammetric peaks. This redox process has also been studied by in situ electrochemical impedance spectroscopy, mass impedance and color impedance at $690 \mathrm{~nm}$. It has been found that crossed impedance functions obtained from the original ones provide interesting information on the participation of both, cations and anions during electrochemical processes.

\section{Introduction}

The hexacyanometallates have generated great interest in recent years due to its interesting properties in the preparation of electrochromic devices or also due to their magnetic properties or their possible application in electrocatalysis, among others ${ }^{1-}$ ${ }^{8}$.These materials correspond to the general simplified formula $M 1_{4}\left(M_{2}(C N)_{6}\right)_{3}$ where M1 and M2 are two different or equal transition metals (Fe, Co, Ni, etc. $)^{9-15}$. Among them, classical Prussian Blue, ferric ferrocyanide $\mathrm{Fe}_{4}{ }^{3+}\left[\mathrm{Fe}^{2+}(\mathrm{CN})_{6}\right]_{3}(\mathrm{~PB})$ is probably the most studied. PB can be generated by following different procedures. On the one side, there is the chemical way, where $\mathrm{PB}$ is spontaneously generated from $\mathrm{FeCl}_{3}$ and $\mathrm{K}_{4} \mathrm{Fe}(\mathrm{CN})_{6}$ solutions. However, for electrochemical studies it proves more interesting the electrochemical way to produce thin films on the surface of different kind of electrode materials. Itaya et al. described a galvanostatic procedure to produce good and controlled quality thin PB films from $\mathrm{FeCl}_{3}$ and $\mathrm{K}_{3} \mathrm{Fe}(\mathrm{CN})_{6}$ in acid aqueous solutions ${ }^{16,17}$. These PB films are generated in the blue mixed valence form, $\mathrm{Fe}^{3+} / \mathrm{Fe}^{2+}$. It is possible electrochemically to reduce $\mathrm{Fe}^{3+}$ sites to $\mathrm{Fe}^{2+}$ and thus obtaining the transparent Everitt's Salt form (ES).

$$
\mathrm{Fe}_{4}^{3+}\left[\mathrm{Fe}^{2+}(\mathrm{CN})_{6}\right]_{3} \cdot m \mathrm{H}_{2} \mathrm{O}+4 \mathrm{~K}^{+}+4 e^{-} \square \quad \mathrm{K}_{4} \mathrm{Fe}_{4}^{2+}\left[\mathrm{Fe}^{2+}(\mathrm{CN})_{6}\right]_{3} \cdot \mathrm{mH}_{2} \mathrm{O}
$$


However, if freshly generated PB films, known as insoluble PB, are cycled around the $P B \square \quad E S$ system some of the $K^{+}$cations which enter the film during the reduction process do not leave the PB film and a new PB structure formula is generated, known as soluble $\mathrm{PB}^{18-20}$. This structure was analyzed by means of high energy X-Ray synchrotron experiments and the $\mathrm{Fe}_{4}^{3+}\left[\mathrm{Fe}^{2+}(\mathrm{CN})_{6}\right]_{3} \mathrm{~K}_{2}\left(\mathrm{OH}^{-}\right)_{2} \cdot \mathrm{mH}_{2} \mathrm{O}$ formula was proposed ${ }^{14,15}$. This soluble $\mathrm{PB}$ can also be reduced to the soluble ES form.

$$
\mathrm{Fe}_{4}^{3+}\left[\mathrm{Fe}^{2+}(\mathrm{CN})_{6}\right]_{3} \mathrm{~K}_{2}\left(\mathrm{OH}^{-}\right)_{2} \cdot \mathrm{mH}_{2} \mathrm{O}+4 \mathrm{~K}^{+}+4 e^{-} \square \quad \mathrm{K}_{4} \mathrm{Fe}_{4}^{3+}\left[\mathrm{Fe}^{2+}(\mathrm{CN})_{6}\right]_{3} \mathrm{~K}_{2}\left(\mathrm{OH}^{-}\right)_{2} \cdot \mathrm{mH}_{2} \mathrm{O}
$$

Stability against successive cycling around the $P B \square \quad E S$ system in acid $K C l$ solutions of these PB films has been tested and proved that more than 10000 cycles are possible with a small loss of electric charge within the voltammetric peaks ${ }^{20}$.

PB films can also be oxidized to the yellow form known as Prussian Yellow (PY). If insoluble $\mathrm{PB}$ films were cycled around the $P B \square \quad P Y$ system, voltammetric peaks decrease quickly and finally the PB film disappears from the surface of the electrode. However, stability against successive cycling around the system $P B \square P Y$ is largely increased if PB films were previously converted to the soluble PB structure. In this last case, some hundreds of cyclic voltammetric peaks could be obtained in some specific experimental conditions without a considerable loss of electric charge ${ }^{20}$. This redox process is accompanied by color changes ${ }^{21}$, thus it is possible to follow the absorbance variation at some characteristic wavelengths and to relate it with the electric current passed during the reduction or oxidation process ${ }^{4}$. PB films change from the blue characteristic color to the yellow form, the maximum of absorbance change during this transition takes place at a wavelength of $690 \mathrm{~nm}^{22-24}$.

Some possible reaction schema for the oxidation to the PY have been proposed in the literature ${ }^{20,25,26}$. The main question is that the balance of the electric charge during the redox process should take place by the participation of cations and/or anions. Transient electrochemical experiments (cyclic voltammetry) where the changes of the mass are in situ monitored by coupling aquartz crystal microbalance (EQCM) proved that the electric charge is compensated mainly by the exchange of cations (potassium if presented in the outer solution $)^{27}$. However at more anodic potentials, a small participation of anions has also been detected ${ }^{28}$.

The study of inorganic films or conducting polymers has attracted many scientific efforts during the last 30 years due to their evident technological interest. Among others, those strategies where in situ signals are recorded together with the electrochemical response have proven to be powerful tools for interpreting and deeper understanding of the electron conduction mechanisms through these films ${ }^{4,22,29-32}$. In EQCM+cyclic voltammetry experiments, the use of the $F d m / d q$ function (mass / electric charge ratio) allows obtaining fast information onthe molar masses of the species involved in the electric charge balance during redox processes of these films ${ }^{28}$. It is similar if the spectroscopic response (absorbance at some characteristic wavelenghts, $A^{\lambda}$ ) is obtained together with the electric response. This information has been proved to be very useful for the deconvolution of overlapped voltammetric waves ${ }^{32}$. In spite of the large amount of information provided by the coupling of transient electrochemical techniques with EQCM or spectroscopic techniques, it is not possible to obtain separated information on the rate of the different overlapped or not processes. For this purpose, it is a better choice the steady-state strategy. In particular, electrochemical impedance spectroscopy (EIS) proved an excellent tool to separate different processes by their relative rates. This is 
accomplished by the change of the frequency of the potential perturbation during the EIS experiment. Thus, information relative only to the fastest processes is obtained at the highest frequencies (double layer charge and uncompensated ohmic drop due to the solution and film resistances, at about $10 \mathrm{kHz}$ ). At lower frequencies, the contribution due to the faradaic processes is obtained, however the possibility of changing the frequency perturbation allows separating between faster and slower processes in many cases. In recent years, the generalization of the impedance to also other analogic signals such as mass or absorbance (color) has allowed a deeper understanding of the electrochemical response of these conducting films at the steady-state ${ }^{27,33-39}$. Mass impedance (MIS) or ac-electrogravimetry and color impedance (CIS) together with the EIS introduce the possibility to obtain crossed impedance function such as

$$
F \frac{\Delta m}{\Delta q}(\omega)=F \frac{1}{j \omega} \frac{\Delta m}{\Delta E} \frac{\Delta E}{\Delta I}(\omega)
$$

clearly related with the molar masses of the involved charged species during the redox processes. Note that the dependence of this function on the perturbation frequency provides information on the cation-anion species participating in the faster-slower faradaic processes.

For the CIS+EIS case, there is the crossed impedance function

$$
F \frac{\Delta A^{\lambda}}{\Delta q}(\omega)=F \frac{1}{j \omega} \frac{\Delta A^{\lambda}}{\Delta E} \frac{\Delta E}{\Delta I}(\omega)
$$

which should be interpreted as an estimation of the electrochromic efficiency ${ }^{40,41}$. In this case, there is also a possible dependence on the frequency of the perturbation enabling separation among the contributions due to faster and slower processes.

The aim of this work is to study the electrochemical, electrogravimetric and spectroelectrochemical behavior of Prussian Blue films at potentials where the $P B \square \quad P Y$ process takes place. These studies were made by both, cyclic voltammetry + spectroscopic in situ and also at steady-state by analyzing the electrochemical impedance spectroscopy together with the ac-electrogravimetry and color impedance at the characteristic wavelength of $690 \mathrm{~nm}$. The coupling of these 3 impedance signals and the use of crossed impedance functions obtained from the 3 primary ones has been proposed some years ago by Gabrielli et $a l^{33}$. It has been used recently for the study of the $P B \square E S$ process in aqueous $\mathrm{KCl}$ solutions and it has been possible to identify different electroactive and electrochromic sites in the $\mathrm{PB}$ structure and to separate their contribution to the overall response $\mathrm{e}^{22,40,41}$. In this work, we have an added difficulty since at these potentials and in the presence of chloride anions in the solution, the gold electrode of the EQCM oxidizes and loses its conductive properties. In order to avoid this problem, $\mathrm{KCl}$ is substituted by $\mathrm{KNO}_{3}$ which does not oxidize the gold electrode, but the stability against successive cycling seems to be not so good as in the case of $\mathrm{KCl}$ solutions.

\section{Experimental}

All chemicals used were Scharlau ${ }^{\mathrm{TM}}$ Analytical Reagent quality. Prussian Blue was deposited from $0.02 \mathrm{M} \mathrm{K}_{3} \mathrm{Fe}(\mathrm{CN})_{6}, 0.02 \mathrm{M} \mathrm{FeCl}_{3}$ and $0.01 \mathrm{M} \mathrm{HCl}$ freshly prepared dissolutions by applying a controlled cathodic current of $40 \mu \mathrm{A} \mathrm{cm} \mathrm{cm}^{-2}$ during $150 \mathrm{~s}$. The 
film thickness was estimated about $115 \mathrm{~nm}^{42-45}$. The PB deposits were sufficiently thin to ensure a precise relationship between the frequency variation of the quartz crystal and the mass change without any viscoelastic artifacts ${ }^{43}$. PB films freshly prepared (insoluble $\mathrm{PB})$ were stabilized and converted into the soluble form by means of cyclic voltammetry around the $P B \square E S$ system ${ }^{20,31,46-48}$ in a $\mathrm{KNO}_{3}$ solution until narrow and sharp peaks appear ( 15 cycles) for the deposits on gold electrode and cycled in a $\mathrm{KCl}$ solution for the ITO electrode studies. All experiments were carried out in $\mathrm{KCl}$ or $\mathrm{KNO}_{3} 0.5 \mathrm{M}$ solutions and at the controlled temperature of $25^{\circ} \mathrm{C}$. The $\mathrm{pH}$ of the solution was set by the addition of the appropriate $1.0 \mathrm{M} \mathrm{HCl}$ or $\mathrm{HNO}_{3}$ solution.

All experiments were carried out in a three electrodes electrochemical cell. The auxiliary electrode was a platinum mesh and the reference the $\mathrm{Ag} / \mathrm{AgCl} / \mathrm{KCl}$ (sat) electrode. The working electrode was an ITO $(1 \mathrm{~cm} \times 1 \mathrm{~cm})$ electrode or the high reflectance gold/quartz crystal electrode (AT cut quartz crystal, $6 \mathrm{MHz}$ or $9 \mathrm{MHz}$, MatelFordahl, France $)\left(0.25 \mathrm{~cm}^{2}\right)$ which allows the simultaneous measure of current, mass (from frequency resonance) and reflectance (from light intensity received on the photodiode surface). The cell temperature was controlled by means of Peltier thermoelectric modules and the cell was a high transmittance glass cell from HELLMA (OG). For the impedance measurements a small potential perturbation was applied to the polarization potential of the working electrode $(25 \mathrm{mV} \mathrm{rms})$.

For acquiring simultaneously the three impedance signals we use a potentiostatgalvanostat PAR $263 \mathrm{~A}$, the generator and four channels frequency response analyzer SOLARTRON 1254 A. The fast mass signal needed is acquired by means of a quartz crystal microbalance (built at UPR 15 CNRS Paris, France) with the frequency reference generator (AGILENT 33220A) together with the home-made frequency comparatorwhich gives an analog voltage signal proportional to the difference between a reference frequency (frequency generator) and the working electrode frequency (EQCM). This equipment requires previous calibration in order to avoid undesired artificial phase shifts in the mass response ${ }^{35,36}$. For the color impedance measurements we use one Spectronic 20 spectrometer conveniently modified: light sensor was replaced by a fast and more sensible photodiode (Silicon PIN photodiode/ OSD100-6) which gives a current proportional to the intensity of the received light. This current was converted into an analogic potential by means of a current to potential converter (home-made). The fast response of this part $\left(10^{-9} \mathrm{~s}\right)$ makes unnecessary a calibration for this equipment.

The above equipments were controlled by means of a Personal Computer-GPIB card and home-made software.

The analysis of experimental data obtained by this assembly requires the use of complex methodologies and in some cases, the use of some numerical procedures to obtain a good fitting of experimental data to the proposed theoretical models. The complete description of both, the methodologies and the equipment used to obtain the three impedance signals simultaneously is described in recent papers ${ }^{33,40,41}$.

The color response received was a light intensity $(I)$ reflected on the surface of the gold electrode of the EQCM. For the color impedance analysis, a small potential perturbation is applied to a steady state system and therefore, only small changes of color (reflected light intensity, $I$ ) are expected. Thus, an apparent increase of absorbance $(\triangle A)$ may be obtained by a first-order Taylor series expansion:

$$
A=-\log \left(I / I_{0}\right)
$$




$$
A+\Delta A=-\log \left(\frac{I+\Delta I}{I_{0}}\right) \approx-\log \left(I / I_{0}\right)-\frac{I_{0}}{I} \Delta I \log (e)=A-B \Delta I
$$

where the absorbance changes ( $\Delta A$ ) may be directly approximated to changes of received light intensity $(\Delta I)$ multiplied by a constant factor $(-B)^{40}, 41$.

For the voltammetric experiments the assembly was the same but absorbance was measured as intensity of transmitted light through the ITO electrode. Absorbance was set to zero at the $-0.2 \mathrm{~V}$ where the PB films are in the transparent ES form.

\section{Results and discussion}

Once PB films were stabilized and converted into the soluble PB form, their electrochemical behavior during the $P B \square \quad P Y$ processes was studied by in situ coupling electrochemical (current) and spectroscopic (absorbance at a given wavelength) responses during a cyclic voltammetry experiment and also at a given potential (steadystate condition) by means of the modulation of the frequency of a small potential amplitude superimposed to the steady-state potential (impedance) recording in situ andtogether, the EIS, MIS and CIS responses.

Before starting the analysis by impedance techniques, PB films deposited on the surface of the transparent ITO electrode were studied by CV + Vis-NIR spectroscopy by coupling a diode spectrometer to our electrochemical cell. In many spectroelectrochemical studies it is preferred to present spectroscopic response as derivative absorbance curves at some characteristic wavelength, and taking advantage of the Faraday's and Lambert-Beer's laws estimating the apparent electrochromic efficiency, $\varepsilon^{\lambda}$ at the characteristic wavelength $\lambda$.

$$
\begin{gathered}
\frac{d q}{d t}=z \mathrm{~F} \frac{d n}{d t} \\
\frac{d A^{\lambda}}{d t}=\varepsilon^{\lambda} \frac{d n}{d t} \\
F \frac{d A^{\lambda}}{d q}=\frac{\varepsilon^{\lambda}}{z}
\end{gathered}
$$

Figure 1 shows as a 3D plot the dependence on the applied potential during a voltammetric oxidation scan $(-0.2 \mathrm{~V} \rightarrow 1.1 \mathrm{~V})$ of $d A^{\lambda} / d t$ at wavelengths between 400 and $950 \mathrm{~nm}$. On this plot, a well-defined mountain is observed at wavelengths between 600 and $750 \mathrm{~nm}$ and the maximum at potentials near $0.2 \mathrm{~V}$ which correspond to the redox potential for the $E S \rightarrow P B$ process where color changes from colorless to the characteristic blue. At more anodic potentials, during the $P B \rightarrow P Y$ oxidation process there is also a color change, from blue to yellow. This is observed by both, a valley at wavelengths between 600 and $750 \mathrm{~nm}$ (blue color disappears) and a mountain at wavelengths between 400 and $500 \mathrm{~nm}$ (yellow color appears). These two electron transitions are clearly interrelated and really correspond to the same electron transitionelectroactive site in the PB structure: 


$$
F e_{l s}^{2+}-C N-F e_{h s}^{3+} \square \quad F e_{l s}^{3+}-C N-F e_{h s}^{3+}+e^{-}
$$

In this equation, the subscripts $l s$ and $h s$ make reference to low spin and high spiniron sites, respectively.

Figure $1 \mathrm{~b}$, represents the voltammetric response for a $\mathrm{PB}$ film in a $\mathrm{KCl}$ solution together with the absorbance derivative curve, $d A^{\lambda} / d t$, at $690 \mathrm{~nm}$ and $430 \mathrm{~nm}$ wavelengths. These wavelengths correspond to the maximum absorbance spectra of the mixed valence form (PB, $690 \mathrm{~nm}$ ) and of the fully oxidized form (PY,430 nm). During the oxidation of ES to the PB form it is observed an important increase of the absorbance at $690 \mathrm{~nm}$ since the transparent blue film undergoes blue. However, this oxidation process produces only smaller changes of absorbance at $430 \mathrm{~nm}$. At largest potentials, during the oxidation $\mathrm{PB} \rightarrow \mathrm{PY}$ there are both, absorbance changes at 690 and at $430 \mathrm{~nm}$, however, at $690 \mathrm{~nm}$ it appears to be a greater signal which is preferred for the color impedance study.

On the other side, redox processes in conducting films are always accompanied by the exchange of counterions to balance electric charge. The general formula proposed for soluble PB films corresponds to $\mathrm{Fe}_{4}^{3+}\left[\mathrm{Fe}^{2+}(\mathrm{CN})_{6}\right]_{3} \mathrm{~K}_{2}\left(\mathrm{OH}^{-}\right)_{2} \cdot \mathrm{mH}_{2} \mathrm{O}$, thus it is possible that the electric charge balance takes place by the main participation of inner potassium cations which leave the PB film during the oxidation process and which are inserted if the film is reduced. In order to corroborate these hypotheses, electrogravimetric studies were also performed. If PB films were deposited on the surface of high reflectance gold EQCM electrodes it is possible to follow in situ and simultaneously the 3 impedance signals, EIS, MIS and CIS ${ }^{22,40,41}$. For these studies we prefer $\mathrm{KNO}_{3}$ solutions to prevent the electrochemical oxidation of the gold electrode at anodic potentials in $\mathrm{KCl}$ solutions. These results are presented in figures $2 \mathrm{a}, 2 \mathrm{~b}$ and $2 \mathrm{c}$ for the EIS (presented as $\left.\frac{\Delta q}{\Delta E}\right)^{40,41}$, for the MIS (presented as $\frac{\Delta m}{\Delta E}$ ) and for the CIS (presented as $\frac{\Delta A^{690}}{\Delta E}$ ), respectively and at the stabilization potential of $0.85 \mathrm{~V}$. At this potential, the MIS loop appears on the $3^{\text {rd }}$ quadrant indicating the main participation of cations as counterions, the CIS appears on the $3^{\text {rd }}$ quadrant also indicating that the absorbance decreases with the applied potential at this wavelength and the electrochemical impedance for conducting polymers always appears on the $1^{\text {st }}$ quadrant. The shape of these loops appears to be slightly different from a 'perfect' circle. This fact may be caused by both, a possible electron or counterion slow transport through the electroactive film and the possibility that more than one redox process takes place simultaneously at these potentials. In order to confirm these hypotheses it is preferred the analysis provided by the crossed impedance functions ${ }^{40,41}$. Figures $3 \mathrm{a}$ and $3 \mathrm{~b}$ represent the dependence on the applied potential of both, the lower frequencies limit of $\left(F \frac{\Delta m}{\Delta q}\right)_{\omega \rightarrow 0}$ and the $\left(F \frac{\Delta A^{690}}{\Delta q}\right)_{\omega \rightarrow 0}$ functions which represent a weighted average of the molar masses of charged species participating and of the electrochromic efficiencies of electroactive sites. In both cases, it appears to be an abrupt change at potentials near $0.925 \mathrm{~V}$. At potentials in the range $[0.700,0.900] \mathrm{V}$, the function $\left(F \frac{\Delta m}{\Delta q}\right)_{\omega \rightarrow 0}$ shows a small variation on the potential reaching values near the $-39 \mathrm{~g} \mathrm{~mol}^{-}$ ${ }^{1}$ which corresponds to the main participation of potassium cation as counterion. However, 
at largest potentials this situation changes and $\left(F \frac{\Delta m}{\Delta q}\right)_{\omega \rightarrow 0}$ undergoes positive after only 50-100 $\mathrm{mV}$. Meanwhile, the variation of $\left(F \frac{\Delta A^{690}}{\Delta q}\right)_{\omega \rightarrow 0}$ on the stabilization potential, shows an increase in the range of $[0.700,0.900] \mathrm{V}$ and also an abrupt change at potentials near $0.925 \mathrm{~V}$.

The abrupt change at potentials near $0.925 \mathrm{~V}$ may be explained by the overlapping of the oxygen evolution at these potentials. An increase in the current should imply a decrease in both ratios, $\left(F \frac{\Delta m}{\Delta q}\right)_{\omega \rightarrow 0}$ and $\left(F \frac{\Delta A^{690}}{\Delta q}\right)_{\omega \rightarrow 0}$ since increases the electric charge passed but not the mass or the color changes. However, the $\left(F \frac{\Delta m}{\Delta q}\right)_{\omega \rightarrow 0}$ reaches positive values which are not compatible with this hypothesis. It is more probable that another redox process takes place at these potentials producing different mass changes and different color changes. One probable explanation compatible with positives values for $\left(F \frac{\Delta m}{\Delta q}\right)_{\omega \rightarrow 0}$ is that anions participate in the redox process. Thus, we can propose that up to potentials near $0.900 \mathrm{~V}$ we have that inner potassium cations leave the PB film during the oxidation,but after all potassium cations have left the PB film it remains $1 / 3$ of the $\mathrm{Fe}^{2+}$ centers not oxidized. Thus, the oxidation of these centers should take place by the participation of other counterions species, or in other words, the anions. This situation explains quite well the variation of the $\left(F \frac{\Delta m}{\Delta q}\right)_{\omega \rightarrow 0}$ values but not directly the abrupt change of $\left(F \frac{\Delta A^{690}}{\Delta q}\right)_{\omega \rightarrow 0}$. To explain this last abrupt change we need to introduce some additional information. During the $P B \square \quad E S$ process, in the potential range $[0.6,0.3] \mathrm{V}$ the $d A^{690} / d t$ does not correspond exactly with the $d q / d t$ (current) curve (Figure $\left.1 \mathrm{~b}\right)^{24}$. There is also that at these potentials the counterions have been identified to be protons or hydrated protons ${ }^{27}$. Thus, we have that there are a part of the sites in the PB form that does not contribute to the blue color of the films and these sites correspond also with the participation of other counterions than the potassium during the $P B \square E S$. We are talking about $\mathrm{Fe}$ sites near the ferrocyanide vacancies in the PB structure which present a different electrochemical and electrochromic behavior and which are responsible of some of the particular properties of these electroactive films ${ }^{22,23}$. Thus, since these $\mathrm{Fe}^{2+}-\mathrm{CN}-\mathrm{Fe}^{3+}$ centers are not 'blue', if oxidized to the $\mathrm{Fe}^{3+}-\mathrm{CN}-\mathrm{Fe}^{3+}$ there is no expected change of absorbance at $690 \mathrm{~nm}$. Thus we can propose for the $P B \square \quad P Y$ process the following reaction schema:

$$
\mathrm{Fe}_{4}^{3+}\left[\mathrm{Fe}^{2+}(\mathrm{CN})_{6}\right]_{3} \mathrm{~K}_{2}\left(\mathrm{OH}^{-}\right)_{2} \cdot \mathrm{mH}_{2} \mathrm{O}+A^{-} \square \quad \mathrm{Fe}_{4}^{3+}\left[\mathrm{Fe}^{3+}(\mathrm{CN})_{6}\right]_{3}\left(\mathrm{OH}^{-}\right)_{2} A^{-} \cdot m \mathrm{H}_{2} \mathrm{O}+2 \mathrm{~K}^{+}+3 e^{-}
$$

This reaction schema is able to explain several experimental results such as the smaller size for the $P B \square P Y$ voltammetric peak if compared with the $P B \square E S$ peak since there are $4 \mathrm{Fe}^{3+}$ sites able to reduce but only $3 \mathrm{Fe}^{2+}$ sites able to oxidize. If we consider also that the oxidation process taking place by the participation of anions seems to not 

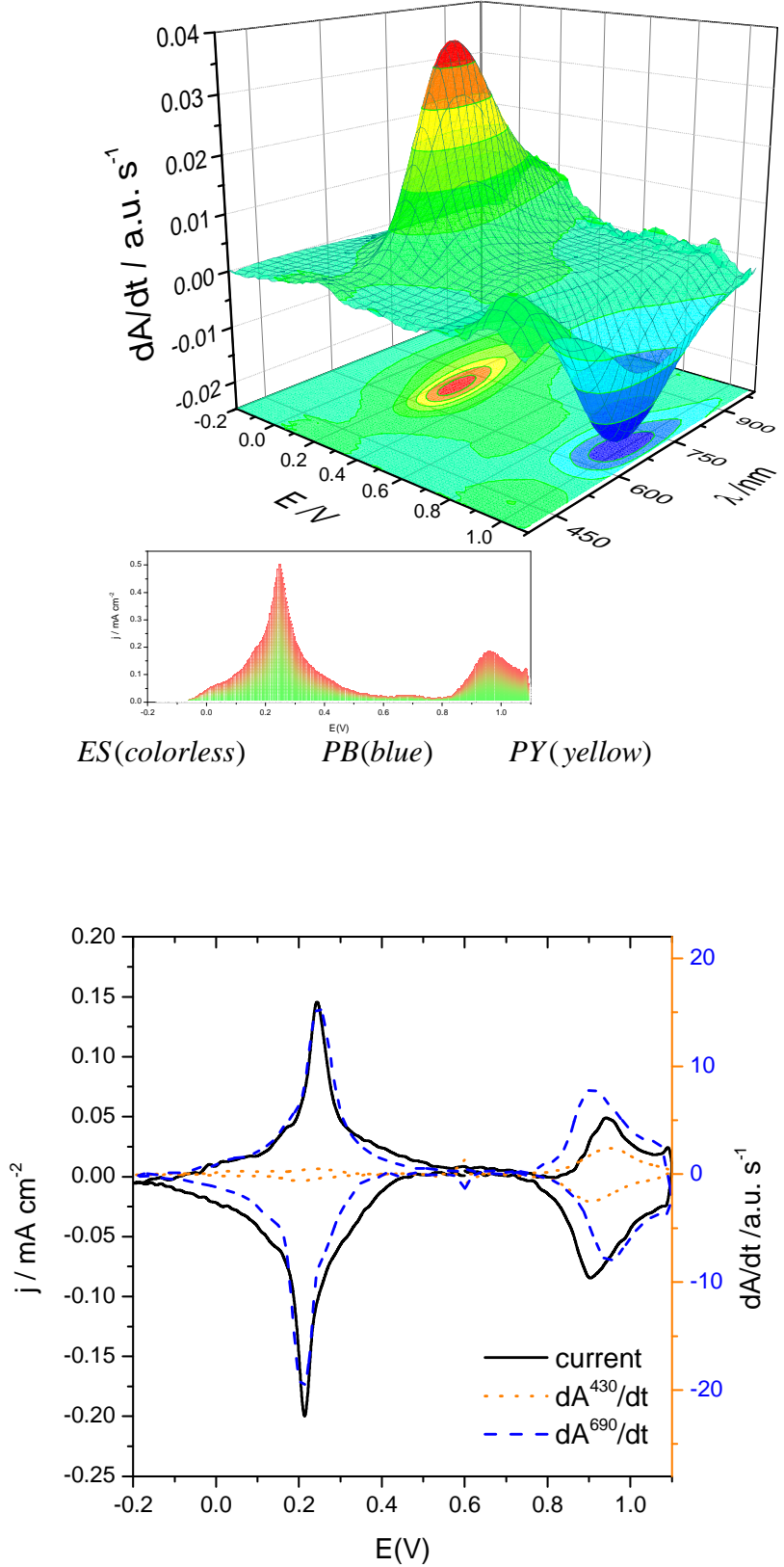

Figure 1 a) Color changes represented as a 3D plot of $d A^{\lambda} / d t$ at wavelengths between 400 and $950 \mathrm{~nm}$ in PB films deposited on ITO electrode during voltammograms from $0.2 \mathrm{~V}(\mathrm{ES})$ until $1.1 \mathrm{~V}(\mathrm{PY})$ in a $\mathrm{KCl}$ solution. b) Cyclic voltammogram $(0.6 \mathrm{~V} \rightarrow$ $0.2 \mathrm{~V} \rightarrow 1.1 \mathrm{~V} \rightarrow 0.6 \mathrm{~V}$ ) of a PB film deposited on ITO electrode with the $d A^{\lambda} / d t$ curves at the characteristic wavelengths of $690 \mathrm{~nm}$ and $430 \mathrm{~nm}$. Scan rate was a) $20 \mathrm{mV} \mathrm{s}^{-1}$ and b) $5 \mathrm{mV} \mathrm{s}^{-1}$. 

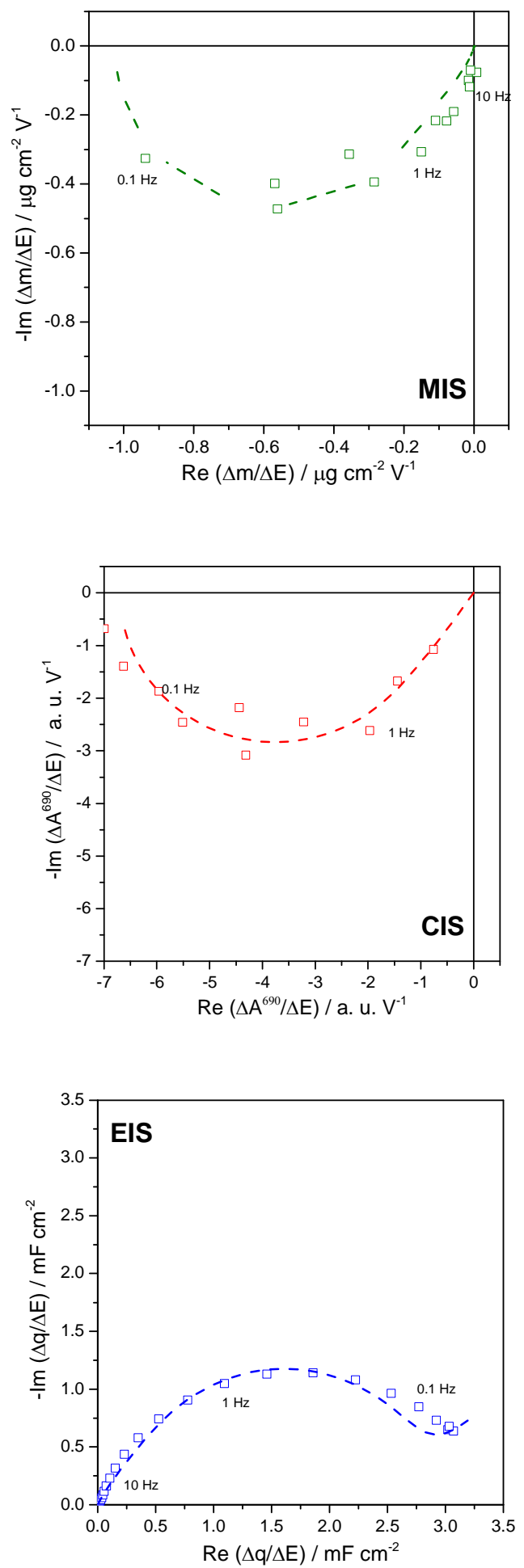

Figure 2. Electrochemical impedance spectroscopy (a), mass impedance (b) and color impedance at $690 \mathrm{~nm}$ (c) for a PB film deposited on a gold EQCM electrode. Stabilization potential was $0.85 \mathrm{~V}$ and the solution was $0.5 \mathrm{M} \mathrm{KNO}_{3} \mathrm{pH}=2.00$. 

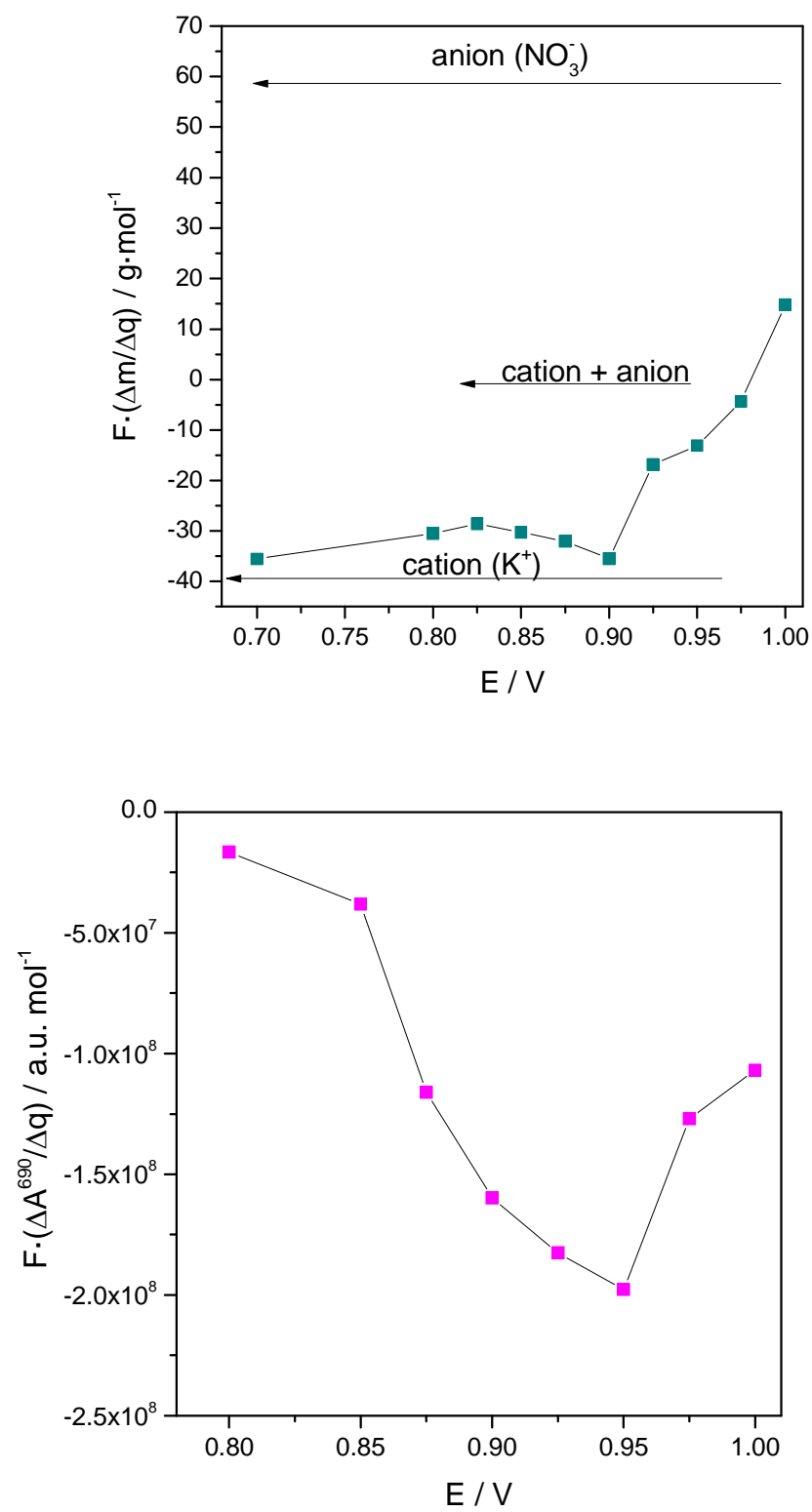

Figure 3. a) Dependence of the crossed impedance function dependence $\left(F \frac{\Delta m}{\Delta q}\right)_{\omega \rightarrow 0}$ on the applied potential. This function is obtained from EIS and MIS experimental data. Horizontal arrows are indicative of the values for a pure participation of potassium or nitrate ions. b) Dependence of the crossed impedance function dependence $\left(F \frac{\Delta A^{690}}{\Delta q}\right)_{\omega \rightarrow 0}$ on the applied potential. This function is obtained from EIS and CIS experimental data. For experimental details see the experimental section.

occur to a great extent, then only a little more of $2 / 3$ of the $F e^{2+}$ are oxidized (potassium participation), that means that the electric charge enclosed in the $P B \square \quad P Y$ should be 
about $\frac{3}{4} \frac{2}{3}=\frac{1}{2}$ of the electric charge enclosed in the $P B \square \quad E S$ voltammogram. This reaction schema explains also the abrupt change of Figures $3 \mathrm{a}$ and $3 \mathrm{~b}$ at potentials near $0.925 \mathrm{~V}$ for the $\left(F \frac{\Delta m}{\Delta q}\right)_{\omega \rightarrow 0}$ and $\left(F \frac{\Delta A^{690}}{\Delta q}\right)_{\omega \rightarrow 0}$ ratios by the overlapping of another electrochemical process with different counterion participation and different electrochromic efficiency.

\section{Conclusion}

The oxidation of Prussian blue films to the yellow form should be described at least as the overlapping of two different redox processes associated to two different electroactive $\mathrm{Fe}^{2+}$ sites. PB films in the soluble form present only $2 \mathrm{~K}^{+}$cations by each 3 $\mathrm{Fe}^{2+}$ sites, implying that we need to consider two different $\mathrm{Fe}^{2+}$ sites within the PB form. This fact is reflected in both, spectroscopic and electrogravimetric changes during electrochemical processes showing a dual behavior: at more cathodic potentials, the redox processes associated to $F e^{2+}$ take place by the participation of potassium cations as counterions and there is a color change from blue to yellow, however after all the potassium cations have left the PB film there is the redox process associated to the other $\mathrm{Fe}^{2+}$ sites where anion participates. Since these centers are not originally 'blue' in the mixed valence PB form, there is no color change associated at this wavelength if oxidized to the fully oxidized form.

\section{Acknowledgments}

Part of this work was supported by CICyT project CTQ2011-28973/BQU. J. A. acknowledges his position to the Ajuntament de València.

\section{References}

1. D. Ellis, M. Eckhoff, and V. D. Neff, Journal of Physical Chemistry, 85, 12251231 (1981).

2. K. P. Rajan and V. D. Neff, Journal of Physical Chemistry, 86, 4361-4368 (1982).

3. P. J. Kulesza, M. A. Malik, S. Zamponi, M. Berrettoni, and R. Marassi, Journal of Electroanalytical Chemistry, 397, 287-292 (1995).

4. P. Kulesza et al., Journal of solid state electrochemistry, 1, 88-93 (1997).

5. O. Sato, T. Iyoda, A. Fujishima, and K. Hashimoto, Science, 271, 49-51 (1996).

6. G. Champion et al., Journal of the American Chemical Society, 123, 1254412546 (2001).

7. P. R. Bueno et al., Journal of the American Chemical Society, 128, 17146-17152 (2006).

8. D. Gimenez-Romero, J. J. García-Jareño, J. Agrisuelas, and F. Vicente, The Journal of Physical Chemistry C, 112, 20099-20104 (2008).

9. J. F. Keggin and F. D. Miles, Nature, 137, 577-578 (1936). 
10. E. R. Ihne and E. W. Kanning, Industrial and Engineering Chemistry, 31, 8891 (1939).

11. M. B. Robin, Inorganic Chemistry, 1, 337-342 (1962).

12. H. J. Buser, D. Schwarzenbach, W. Petter, and A. Ludi, Inorg. Chem., 16, 2704-2710 (1977).

13. F. Herren, P. Fischer, A. Ludi, and W. Halg, Inorganic Chemistry, 19, 956-959 (1980).

14. F. F. Ferreira et al., Applied Physics Letters, 92 (2008).

15. P. R. Bueno et al., Journal of Physical Chemistry C, 112, 13264-13271 (2008).

16. K. Itaya, H. Akahoshi, and S. Toshima, Journal of the Electrochemical Society, 129, 1498-1500 (1982).

17. K. Itaya, T. Ataka, and S. Toshima, Journal of the American Chemical Society, 104, 4767-4772 (1982).

18. A. Hamnett, S. Higgins, R. Mortimer, And D. Rosseinsky, Journal of Electroanalytical Chemistry, 255, 315-324 (1988).

19. A. Roig, J. Navarro, R. Tamarit, and F. Vicente, Journal of Electroanalytical Chemistry, 360, 55-69 (1993).

20. A. Roig, J. Navarro, J. J. Garcia, and F. Vicente, Electrochimica Acta, 39, 437442 (1994).

21. R. J. Mortimer, D. R. Rosseinsky, and A. Glidle, in Symp on Fundamentals of Electrochromic Devices at the 1990 Annual Meeting of the American Inst of Chemical Engineers, p. 211-223, Chicago, Il (1990).

22. J. Agrisuelas, J. J. García-Jareño, and F. Vicente, J. Phys. Chem. C, 116, 19351947 (2012).

23. P. R. Bueno et al., The Journal of Physical Chemistry C, 113, 9916-9920 (2009).

24. J. Agrisuelas et al., Journal of the Electrochemical Society, 156, P74-P80 (2009).

25. K. Itaya, K. Shibayama, H. Akahoshi, and S. Toshima, Journal of Applied Physics, 53, 804-805 (1982).

26. J. J. GarciaJareno, J. NavarroLaboulais, and F. Vicente, Electrochim. Acta, 41, 2675-2682 (1996).

27. C. Gabrielli, J. J. Garcia-Jareno, M. Keddam, H. Perrot, and F. Vicente, The Journal of Physical Chemistry B, 106, 3182-3191 (2002).

28. J. Agrisuelas et al., J. Electrochem. Soc., 154, F134-F140 (2007).

29. A. R. Hillman, M. J. Swann, and S. Bruckenstein, Journal of Physical Chemistry, 95, 3271-3277 (1991).

30. A. R. Hillman, N. A. Hughes, and S. Bruckenstein, Analyst, 119, 167 (1994).

31. B. J. Feldman and O. R. Melroy, Journal of Electroanalytical Chemistry, 234, 213-227 (1987).

32. J. Agrisuelas, D. Giménez-Romero, J. J. García-Jareño, and F. Vicente, Electrochemistry Communications, 8, 549-553 (2006).

33. C. Gabrielli, M. Keddam, H. Perrot, and R. Torresi, Journal of Electroanalytical Chemistry, 378, 85-92 (1994).

34. P. Bernard Et Al., Electrochimica Acta, 36, 743-746 (1991).

35. C. Gabrielli, M. Keddam, N. Nadi, and H. Perrot, Electrochimica Acta, 44, 2095-2103 (1999).

36. J. J. García-Jareño et al., Electrochimica Acta, 45, 3765-3776 (2000). 
37. C. Gabrielli, J. J. Garcia-Jareno, M. Keddam, H. Perrot, and F. Vicente, The Journal of Physical Chemistry B, 106, 3192-3201 (2002).

38. D. Benito et al., Electrochemistry Communications, 4, 613-619 (2002).

39. J. J. Garcia-Jareno et al., The Journal of Physical Chemistry B, 107, 1132111330 (2003).

40. J. Agrisuelas, J. J. García-Jareño, D. Gimenez-Romero, and F. Vicente, The Journal of Physical Chemistry C, 113, 8438-8446 (2009).

41. J. Agrisuelas, J. J. García-Jareño, D. Gimenez-Romero, and F. Vicente, The Journal of Physical Chemistry C, 113, 8430-8437 (2009).

42. J. J. García-Jareño, J. Navarro-Laboulais, and F. Vicente, Electrochimica Acta, 42, 1473-1480 (1997).

43. J. J. García-Jareño, C. Gabrielli, and H. Perrot, Electrochemistry Communications, 2, 195-200 (2000).

44. J. J. García-Jareño, J. J. Navarro, A. F. Roig, H. Scholl, and F. Vicente, Electrochimica Acta, 40, 1113-1119 (1995).

45. J. J. García-Jareño, A. Sanmatías, J. Navarro-Laboulais, and F. Vicente, Electrochimica Acta, 44, 4753-4762 (1999).

46. R. J. Mortimer and D. R. Rosseinsky, Journal of the Chemical Society-Dalton Transactions, 2059-2061 (1984).

47. C. A. Lundgren and R. W. Murray, Inorganic Chemistry, 27, 933-939 (1988).

48. A. Hamnett, S. Higgins, R. S. Mortimer, and D. R. Rosseinsky, Journal of Electroanalytical Chemistry, 255, 315-324 (1988). 